\title{
Tricalcium Phosphate - Magnesium Interface: Microstructure and Properties
}

Mariano Casas Luna, ${ }^{1, a}$, Edgar B. Montúfar ${ }^{1, b}$, Miroslava Horynováa ${ }^{1, c}$, Pavel Gejdos ${ }^{1, d}$, Lenka Klakurková ${ }^{1, e}$, Sebastián Díaz de la Torre ${ }^{2, f}$, Jozef Kaiser ${ }^{1,9}$, Ladislav Celko ${ }^{1, h}$.

${ }^{1}$ CEITEC - Central European Institute of Technology, Brno University of Technology, Technická 3058/10, 61600 Brno, Czech Republic.

${ }^{2}$ Instituto Politécnico Nacional México. Centro de Investigación e Innovación Tecnológica CIITECIPN. Cerrada de Cecati S/N. Col. Santa Catarina. Del. Azcapotzalco CP. 02250, Mexico City, Mexico.

amariano.casasluna@ceitec.vutbr.cz, beb.montufar@ceitec.vutbr.cz, cmiroslava.horynova@ceitec.vutbr.cz, ${ }^{\mathrm{d} P a v e l . G e j d o s @ c e i t e c . v u t b r . c z, ~}$

elenka.klakurkova@ceitec.vutbr.cz, 'sediazt@yahoo.com.mx, 9jozef.kaiser@ceitec.vutbr.cz, hcelko@fme.vutbr.cz

Keywords: Calcium phosphate, Magnesium, Interface, Hardness.

Abstract. The fabrication of a composite material based on magnesium $(\mathrm{Mg})$ and tricalcium phosphate is reported in this work. Rods of $\beta$-tricalcium phosphate ( $\beta$-TCP) were processed and consolidated together with pure $\mathrm{Mg}$ powder through spark plasma sintering (SPS). The microstructure at the interface, the chemical composition and transformation of the components and the microhardness were analysed. The microstructure of the composite shows two zones with welldefined and continuous interface between them: a ceramic zone composed by $\beta$-TCP filled with $\mathrm{Mg}$ and the metallic zone constituted by $\mathrm{Mg}$ and $\mathrm{Mg}$ rich eutectic. Vickers hardness shows the excellent mechanical interaction between the two zones.

\section{Introduction}

Calcium phosphate biomaterials, such as $\beta$-tricalcium phosphate $(\beta$-TCP), has been widely used as bone substitute material in clinic applications because of their excellent biocompatibility [1]. Unfortunately, its poor mechanical behaviour limits its use for bone regeneration in load-bearing sites [2]. Recently magnesium $(\mathrm{Mg})$ and its alloys have been attracted attention as biodegradable implants, as they have similar mechanical properties to natural bone [3,4].

The inconvenient of $\mathrm{Mg}$ and its alloys is the low corrosion resistance in body fluids. In this field, several researches have been focused in the coating of $\mathrm{Mg}$ bodies mainly with calcium phosphates, in order to improve the corrosion resistance $[5,6]$. In those studies, the physical, chemical and biological characterisation of the composite materials have been reported [6-8]. Nevertheless, into the knowledge of the authors, the interface between the calcium phosphate and Mg phases has not been extensively analysed.

Considering that the interface in any composite material is one of the most important features due to all the interactional phenomena take place in this region, the present study is focused in the characterization of the interface between $\beta$-TCP and Mg. To this end, $\beta$-TCP-Mg composites were consolidated through spark plasma sintering at $670{ }^{\circ} \mathrm{C}$. The interface $\beta$-TCP - Mg has been analysed by scanning electron microscopy (SEM), X-ray diffraction (XRD) and also the microhardness testing has been performed, either, in the metallic or ceramic component, or the interface between them.

\section{Experimental Procedure}

Materials. Pure $\beta$-TCP powder (VWR Chemicals, Belgium) was mixed with a binder (Pluronic F-127, Sigma Aldrich, Germany) for its extrusion into rods $(250 \mu \mathrm{m}$ in diameter and $5 \mathrm{~mm}$ in 
length). After that, the rods were sintered at $1100^{\circ} \mathrm{C}$ per 5 hours and placed together with pure $\mathrm{Mg}$ powder (Riedel de Haen S030195, Germany) inside of a graphite die for its consolidation.

Sintering conditions. Consolidation of TCP-Mg specimens was conducted using a commercial spark plasma sintering (SPS) system (Dr. Sinter 1050, Japan). The sintering temperature was set up at $670{ }^{\circ} \mathrm{C}$ in order to melt the $\mathrm{Mg}$ powder without thermal degradation of $\beta$-TCP. A heating rate of $100{ }^{\circ} \mathrm{Cmin}^{-1}$ was followed till reaching the sintering temperature under vacuum $(15 \mathrm{~Pa})$, in which, a holding time of 3 minutes was sustained. No load on the specimens was applied during sintering and the final dimensions of the consolidated specimens were $10 \mathrm{~mm}$ in diameter and $20 \mathrm{~mm}$ in length.

Characterisation. Sintered $\beta$-TCP-Mg cylinders were cut longitudinally and polished with $\mathrm{SiC}$ paper and diamond suspensions till 1-micron finished. The microstructure of polished surfaces was characterized by SEM (LYRA3 XMU, TESCAN). The Vickers hardness of polished samples was measured using a Vickers pyramidal microhardness indenter (STRUERS DuraScan-70), using $300 \mathrm{~g}$ of load for $10 \mathrm{sec}$. Minimums of seven measurements were practiced on each region of the samples, and the average was used to report Vickers hardness in MPa. XRD analysis was conducted on a Rigaku SmartLab $3 \mathrm{~kW}$ apparatus, using Cu-radiation to follow any phase transformation or reactions between the ceramic and metallic components.

\section{Results and Discussions}

The microstructure of the $\beta$-TCP - Mg composite revealed two main areas along the specimen (see Fig. 1). One area corresponds to the ceramic phase, composed mainly by $\beta$-TCP rods with metallic $\mathrm{Mg}$ inside its micropores. The microstructure of $\mathrm{Mg}$ inside $\beta$-TCP rods seems to correspond to pure $\mathrm{Mg}$ or solid solution of $\mathrm{Ca}$ in $\mathrm{Mg}(\mathrm{Mg}$ can dissolve around 0.82 atomic \% of $\mathrm{Ca}$ [9]). However, this could not be corroborated by EDS, because the minimum area that can be analysed with our system was larger than the size of this phase in the microstructure. The second area in the microstructure corresponds to the metallic phase, presenting pure $\mathrm{Mg}$ and $\mathrm{Ca}+\mathrm{Mg}$ islets. More detail microstructural analysis of the islets revel that are composed by pure $\mathrm{Mg}$ and $\mathrm{Mg}-\mathrm{CaMg}_{2}$ eutectic phase. Probably the $\mathrm{CaMg}_{2}$ intermetallic was formed by partial dissolution and diffusion of $\mathrm{Ca}$ from the $\beta$-TCP component. In fact, the binary system $\mathrm{Mg}-\mathrm{Ca}$ presents two eutectic points, the Mg-rich eutectic point is placed at 10.5 atomic $\%$ of $\mathrm{Ca}$ and $516.5^{\circ} \mathrm{C}$ (eutectic melting point) [9]. Therefore, the formation of this eutectic during spark plasma sintering condition used in this work is thermodynamically feasible.

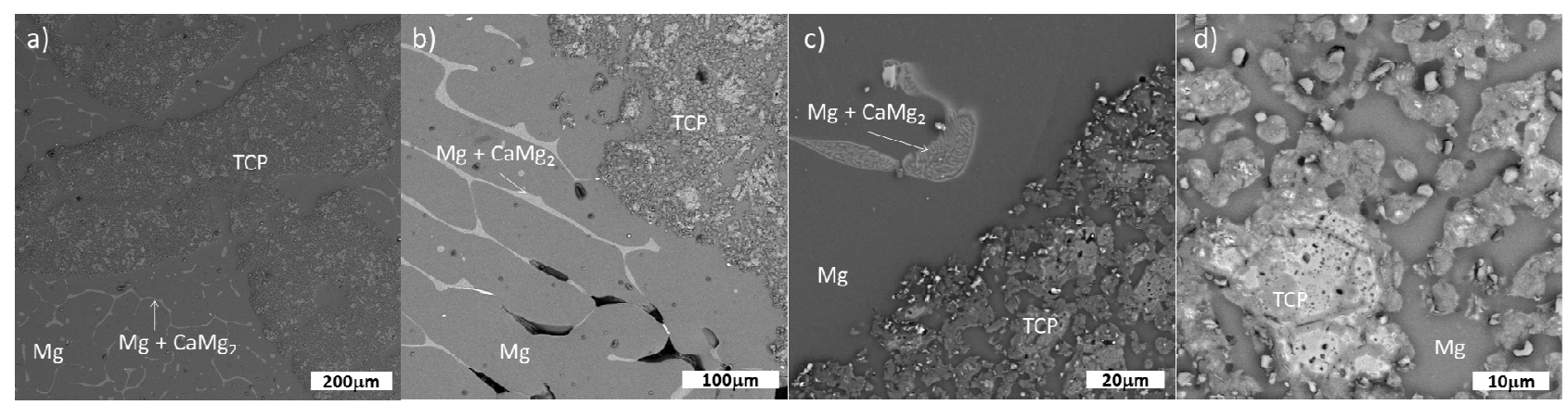

Fig. 1. Representative SEM pictures of $\beta$-TCP $-\mathrm{Mg}$ composite, after being consolidated by SPS during 3 min at $670{ }^{\circ} \mathrm{C}$, under vacuum. In a) an overall view of the composite is showed, where ceramic and metallic components can be localized along the sample. In pictures b) and c) a detail of the interface between the $\mathrm{Mg}$ and the $\beta-T C P$ is observed, revealing the presence of porosity in the metallic phase and also, the presence of the eutectic microstructure $(\mathrm{Mg}+\mathrm{CaMg} 2)$. d) It is a detailed picture from the ceramic phase, the presence of $\mathrm{Mg}$ inside of the small porous of the $\beta$-TCP rod can be appreciated.

The XRD analysis of the consolidated $\beta$-TCP - Mg composites (Fig. 2) corroborate the presence of the $\mathrm{CaMg}_{2}$ intermetallic observed by SEM. It may be expected that the loss of Ca can lead on the partial phase transformation into other calcium phosphates or the decomposition of $\beta$-TCP. 
Nevertheless, no characteristics pics of other phases were found by XRD. It is probable that ionic exchanges occurred during sintering leading on the substitution of $\mathrm{Ca}$ with $\mathrm{Mg}$ in the $\beta$-TCP crystalline lattice. In fact, $\mathrm{Mg}$ is considered as a stabilizer of the beta phase of tricalcium phosphate [10]. On the other hand, although the vacuum process, a partial oxidation of $\mathrm{Mg}$ was observed.

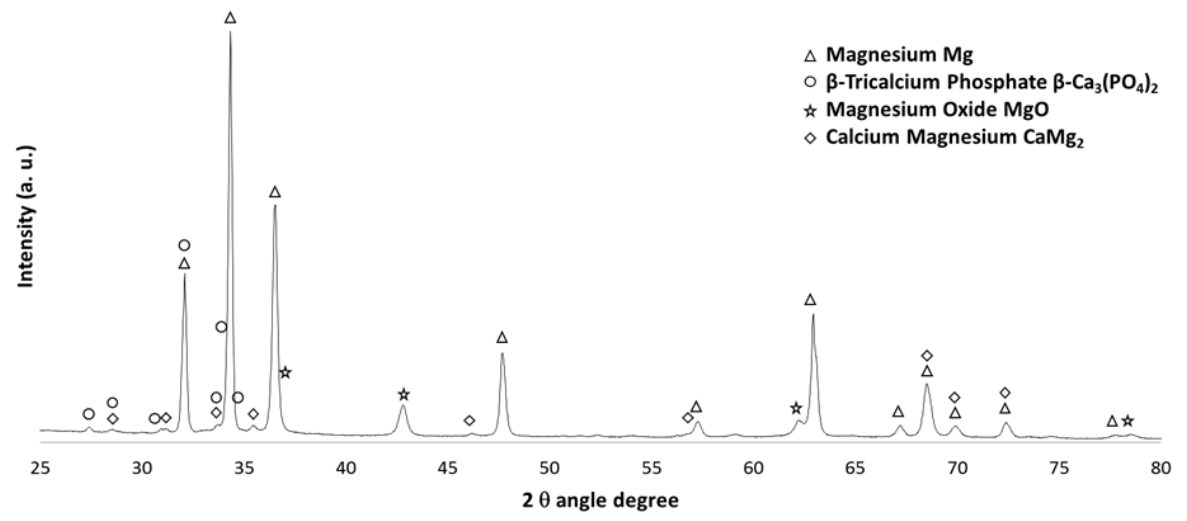

Fig. 2. XRD patterns of $\beta$-TCP $-\mathrm{Mg}$ composite after being consolidated by SPS during 3 min at $670{ }^{\circ} \mathrm{C}$, under vacuum.

The interface between the metallic and ceramic components was well defined in the microstructure (see Fig. $1 \mathrm{~b}$ and c). The trabecula forming the $\beta$-TCP rods define a clear boundary between $\beta$-TCP and Mg. Nonetheless, Mg penetrates into the ceramic filling its micropores. In other words, $\mathrm{Mg}$ forms a continue matrix that envelops the $\beta$-TCP rods but as well infiltrates into the rods. The penetration of $\mathrm{Mg}$ in $\beta$-TCP microporosity produced a good contact between the two components. This can represent a significant advantage from the mechanical point of view, because the metallic component can tough the ceramic component, leading on improved mechanical strength respect the metallic component in close contact with the ceramic but without penetration in its microstructure.

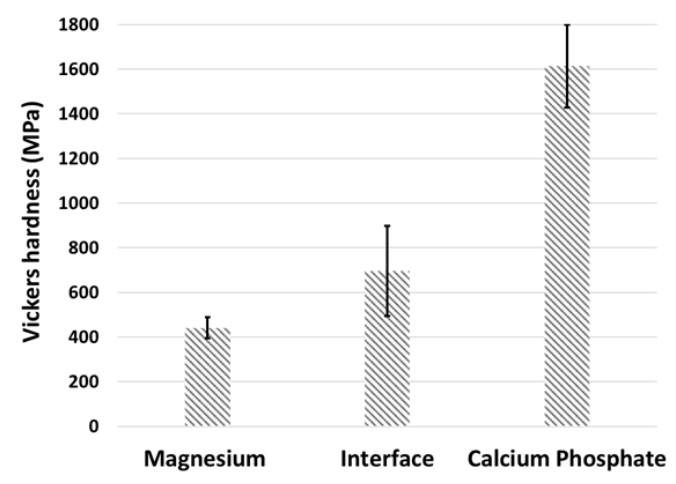

Fig. 3. Vickers hardness of $\beta$-TCP $-\mathrm{Mg}$ composite in the three different points: ceramic, metallic and the $\mathrm{TCP}-\mathrm{Mg}$ interface. Bars indicate the standard deviation of the experimental data.

The hardness of the composite was measured in the ceramic and metallic areas as well as in their interface. The results are shown in Fig. 3. The highest hardness corresponds to the $\beta$-TCP component with average of $1614 \mathrm{MPa}$. Besides, no cracks propagation in the ceramic part has been perceived, this can be also attributed to the presence of $\mathrm{Mg}$ in the microporosity of the $\beta$-TCP rod. In contrast, the lowest hardness corresponds to the $\mathrm{Mg}$ component with an average value of $441 \mathrm{MPa}(44.9 \mathrm{HV})$. In this case, the experimental hardness is a little bit higher than the one reported for pure $\mathrm{Mg}$ (around $40 \mathrm{HV}, 392.3 \mathrm{MPa}$ ) [11]. An intermediate hardness, average value of $695 \mathrm{MPa}$, was measured in the $\beta$-TCP - Mg interface, showing a mixed mechanical behaviour but as well a good mechanical contact between ceramic and metallic components of the composite. The 
higher standard deviation in hardness were observed for the interface and the $\beta$-TCP component. This behaviour is assigned to the microstructure of $\beta$-TCP rod with pores of heterogeneous size filled with $\mathrm{Mg}$, which jeopardize the result depending on the area in which the hardness measurement was performed.

\section{Conclusions}

The microstructure of the $\beta$-TCP - Mg composite revealed two zones with well-defined and continuous interface between them: a ceramic zone composed by $\beta$-TCP filled with $\mathrm{Mg}$ and the metallic zone constituted by $\mathrm{Mg}$ and $\mathrm{Mg}$ rich eutectic. The formation of this eutectic is ascribed to $\mathrm{Ca}$ diffusion from the $\beta$-TCP rods. Vickers hardness corroborate the excellent mechanical interaction between the two zones. Besides, no crack propagation in the ceramic zones was observed during indentation, due to the presence of $\mathrm{Mg}$ in the microporosity of the $\beta$-TCP.

\section{Acknowledgements}

This project has received funding from the European Union's Horizon 2020 research and innovation programme under the Marie Skłodowska-Curie and it is co-financed by the South Moravian Region under grant agreement no. 665860. To the financial support provided through project CEITEC 2020 (LQ1601) with financial support from the Ministry of Education, Youth and Sports of the Czech Republic under the National Sustainability Programme II. Part of the work was carried out with the support of core facilities of research infrastructure CEITEC Nano of CEITECBUT. MCL acknowledges to Brno Ph. D. Talent scholarship founded by the Brno City Municipality. SDT acknowledges to Conacyt Mexico, through the project CB.177700, and COFAA-IPN (SIP project 20144443).

\section{References}

[1] M. Espanol, R.A. Perez, E.B. Montufar and M.P. Ginebra in: Biomimetic, Bioresponsive, and Bioactive Materials: An Introduction to Integrating Materials with Tissues, edited by $\mathrm{M}$. Santin and G.J. Phillips. John Wiley \& Sons, Hoboken, New Jersey (2012).

[2] J. A. Juhasz, S. M. Best: J. Mater Sci. Vol. 47 (2012), p. 610.

[3] J.X. Yang, Y.P. Jiao, F.Z. Cui, In-Seop Lee, Q.S. Yin and Y. Zhang: Surface and Coatings Technology. Vol. 202 (2008), p. 5733.

[4] N. Travis Kirkland and N. Birbilis: Magnesium Biomaterials. Design, Testing, and Best Practice (Springer publications, Cham, Heidelberg, New York, Dordrecht, London 2014).

[5] L. Xu, F. Panc, G. Yu, L. Yang, E. Zhang and K. Yang: Biomater, Vol 30 (2009), p. 1512.

[6] Z. Li, X. Gu, S. Lou and Y. Zheng: Biomater. Vol. 29 (2008), p. 1329.

[7] J. Wei, J. Jia, F. Wu, S. Wei, H. Zhou, H. Zhang, J.-W. Shin and C. Liu: Biomater. Vol 31 (2010), p. 1260.

[8] F. Witte, F. Feyerabend, P. Maier, J. Fischer, M. Stormer, C. Blawert, W. Dietzel and N. Hort: Biomater. Vol 28 (2007), p. 2163.

[9] A. A. Nayeb-Hashemi and J. B. Clark: Bulletin of Alloy Phase Diagrams. Vol. 8 (1987), p. 58.

[10] J.C. Araújo, M.S. Sader, E.L. Moreira, V.C. a. Moraes, R.Z. LeGeros and G. a. Soares: Mater. Chem. Phys. Vol 118 (2009), p. 337.

[11] H. Ferkel and B.L. Mordike: Mater. Sci. and Eng. A. Vol. 298, 1-2 (2001), p.193. 